\title{
A Study on the Path of Strategic Transformation of Chinese Private Universities in the Background of Digital era
}

\author{
Jizheng $\mathrm{Ma}^{1, \mathrm{a}}$ \\ 1'incheng College of Si Chuan University, Cheng Du, China \\ a340697191@qq.com
}

Keywords: Digital era, Private Universities, Strategic Transformation, Path

\begin{abstract}
The technological change in the digital era has brought unprecedented impact on higher education from educational contents and forms. The nature of Chinese private universities determines the strong internal driving force of the strategic transformation. Private universities take the needs of learners as the starting point, reconstruct higher education content, teaching methods, operation process through the internet, big data and other technologies, provide accurate customized life-long education products and services for the learners; Build a flexible management model centered on teaching and research, establish an open and dynamic mutual learning space and humanities community, and become a think tank of local economic development.
\end{abstract}

\section{数字时代背景下中国民办高校战略转型发展的路径研究}

\author{
马继征 $1, a$ \\ 1 四川大学锦城学院, 成都, 四川, 中国 \\ a340697191@qq.com
}

关键词：数字时代; 民办高校; 战略转型;实现路径

中文摘要: 数字时代的技术变革从教育内容与教育形式对高等教育都带来了前所未有的冲击。 中国民办高校的性质决定了其具有战略转型的强烈内在驱动力。民办高校以学习者的需求为 出发点, 通过互联网、大数据等技术重构高等教育的教育内容、教学方式与运作流程, 为学 习者提精准的定制化终身教育产品与服务; 通过价值链分析构建以教学科研为中心的柔性管 理模式, 建立一个开放的、充满活力的互助式学习空间与人文社区, 并成为地方经济发展的 智库。

\section{1. 引言}

以移动互联网、大数据、云计算、人工智能为代表的信息技术的飞速发展, 对当今社会 的任何产业都带来了巨大的变革, 高等教育也同样面临着前所未有的冲击。

教育内容上, 技术的革命引发产业的更迭, 产业的更迭进一步导致岗位升级、换代甚至 消失; 因此高校部分专业的课程体系与教学内容都面临着数字时代下的变革。

教育形式上, 工业时代产生的标准化教育体系已经无法适应数字智能时代的个性化培养 要求; 在线公开课程、慕课、微学位课程等的大规模兴起, 使得知识的获取更加便捷与专业, 高校已经不再是知识的唯一代理商, 人们可以通过网络获得世界范围内的优质教育资源。 


\section{2. 数字时代背景下民办高校战略转型的内在动力}

中国民办高校经过近三十年的发展，截止2015年全国民办高校734所，占全国高校总数的 $28.7 \%$, 在校生 610.90 万人, 占到高校总在校生的 $23 \%$ 。民办高校也成为中国高等教育的重要 组成部分, 其扩大了高等教育资源, 增加了高等教育资源供给的形式和内容, 培养了大批经 济建设和社会发展需要的应用型人才。但不可否认的是, 民办高校在发展中依旧存在着一定 的问题与困难。而数字时代下的洪水, 最先冲击的必将是整个高等教育体系中的最薄弱的环 节。

面对时代的变迁, 民办高校具有强大的内在动力进行战略转型。首先民办高校的生源处 于整个高考分数体系中的末端, 随着人口红利的逐渐消失与高等教育多样化的选择渠道, 决 定民办高校生存可能性的生源竞争日趋白热化，而竞争反过来驱动民办高校寻求自身发展; 其次, 民办高校的生存危机感非常强烈, 从创办者到教职员工有着强烈的忧患意识和改革创 新精神; 最后民办高校具有类企业特征, 是自负盈亏的经济实体, 运营效率的最大化与利润 追求促使其选择改革发展。

\section{3. 民办高校战略转型的目标设定}

民办学校发展初期多数还在为基本的生存与发展努力, 往往专注于规模效应; 当规模基 本均衡后, 部分民办高校逐步寻求作为应用型教育的特色作为目标; 但数字化时代, 随着技 术的发展, 逐步解构了传统高等教育的发展模式, 民办高校又该何进行战略转型的目标设定?

首先，无论网络与技术如何颠覆不同行业的运行规律，作为高校的核心价值依旧是教育 服务的供给, 只是随着时代的变革, 高等教育也将从知识驱动走向智慧驱动, 从规模驱动、 标准化供给向质量驱动、定制化供给转变; 其次, 高校虽不再是知识的唯一代理商, 但其独 有的物理空间构筑成的智慧与创意的交流空间，是任何在线教育难以取代的; 同时，高校不 应拒绝任何形式的教育资源, 而要成为各类教育资源的共享空间; 最终, 民办高校也要逐步 而承担其为服务社会与推动教育发展的责任。

为在数字时代的浪潮中砥砺前行，作为民办高校的战略转型目标可制定为：定制化的教 育服务的生产者; 智慧碰撞的校园人文社区; 优质教育资源共享的开放型学习空间; 教育与 产业互动、服务于地方发展的智库; 先进教学模式的研究与输出基地。

\section{4. 数字时代背景下中国民办高校战略转型的实现路径}

民办高校具有类企业特性，借用美国著名战略学家迈克尔・波特提出的“价值链分析法”， 把高校内外价值增加的活动分为基本活动和支持性活动, 基本活动涉及教育服务的供给、科 研服务的供给、校园文化的建设、智慧校园的建设; 支持性活动涉及组织与管理、品牌与公 共关系、监测与反馈。通过价值链各个价值活动环节, 形成民办高校战略转型的实现路径。

\section{1 教育服务的供给}

高等教育的核心价值是人才培养，呈现形式即教育服务的供给，这一点很难随着技术的 发展、时代的变迁而改变。改变的是教育服务提供的内容与形式, 首先要提供适应时代发展 的教育内容, 其次要打破原有统一化的教育服务供给模式, 调整教育服务的内容, 使其实现 个性化教育服务。

\subsection{1 建立课程开发中心}

专业是由课程组成, 课程质量决定了教育服务的内容与质量。个性化教育内容的供给, 首先从课程改革着手, 建立课程开发中心, 而课程开发的前提是行业需求分析与学生需求分 析: 首先行业需求分析是对各个行业发展现状及前景的调研, 对行业中人才需求的数量与任 职要求进行分析, 作为课程开发的基础; 其次通过数据与诊断分析, 发现每个学生的个性、 
特长与潜质, 建立学生个人学业与职业规划; 最后, 基于产业发展与人才需求预测, 开发或 更新课程及课程体系，逐步形成跨学科的新兴专业，以实现人才培养的时代适应性。

同时开发终身教育产品，将符合市场需求的课程进一步产品化，包括线教育课程及教辅 产品，逐步建立具有民办高校特色与优势的应用型终身教育线上产品体系。

4.1 .2 通识教育+专业教育+选修教育+实习实践的培养体系

完善的通识教育: 增加信息技术素养、人文素养、跨文化交流能力、创新创意能力、学 习迁移能力等的教育，学生在通识教育中进一步探索自身定位专业;

前沿的专业教育：增强专业知识的更新速度及与产业发展趋势的对接;

模块化的选修课程体系: 学生根据个人规划选修适于个人发展的课程体系, 保证每个个 体的充分发展，协助学生构建符合社会需求的跨学科知识结构体系;

多元化的实习实践体系：应用环节中对于所学知识的应用, 除了原有的实习环节, 增加 创业、项目开发，应用型科研等多种可选择的方式，实现人才的分类发展。

4.1.3 教学方法的变革

除了教学内容与结构的调整, 教学方法同样也会对教育效果产生不同的影响, 随着数字 时代背景下技术的更新, 可利用的教学资源的丰富, 教学方法也应随之变革。

深度学习的翻转课堂: 打造以学生为主体的翻转课堂, 教师注重组织、设计课堂教学, 建立探究式的学习环境; 利用信息技术将记忆、理解的内容让学生自学, 而课堂上更多是应 用、分析、评价、创造层面的深度学习。

线上线下结合的互助式学习空间: 通过海量数字学习资源库, 互联网化的学习平台等现 代化手段，实现社交化学习、及时反馈、在线答疑、问题分答的互助式学习空间。

教师身份的转变: 提供多元化的支持服务, 是教学的设计者、活动的组织者和学习的引 导者, 运用技术与教学的融合提高教学效果。

\section{2 科研服务的供给}

民办高校的科研应该立足于教育与产业互动，成为服务于地方发展的智库。

科研服务的重心: 服务地方发展的应用型科研、各专业领域的科学研究、应用型教育研 究;

研究中心的建立: 除各分院在专业领域的研究中心外, 学校层面采用灵活机制建立产业 发展研究中心、教育与教学研究中心、大数据中心、高校战略发展研究中心等, 成为教育与 产业发展对接的纽带;

研究成果指导教学改进的机制：形成研究与教学双向互动的机制;

共享共建研发基地: 与企事业共享共建, 资源共享的研发基地, 提高为社会服务的效率。

\section{3 智慧校园的建设}

互联网、大数据、人工智能背景下，民办高校首先要的在校园建设上要以服务为导向， 建立大数据中心、互联网化教学平台、数字资源库、信息化管理服务系统, 形成人-信息-物 理间融合贯通的智慧型校园空间。

大数据中心要建立基于学生校园学习生活的, 连贯的全过程的数据采集、管理与分析的 大数据中心, 为提供个性化教育服务, 为管理决策等提供依据; 互联网化教学平台实现在线 的互动教学与学习, 实现信息技术与教学、管理、评价、监控体系等关键环节的深度融合, 以优化教学与考评模式, 提升教学质量与效率; 数字资源库要建立教学数字资源库; 建立基 于地方经济建设的, 涵盖相关行业发展的信息资源库; 建立应用型人才培养相关研究的数字 资源库等; 信息化管理服务系统实现高效的教学、师资、后勤保障等公共服务的信息化体系。 


\section{4 校园社区文化的建设}

在数字化时代，尽管知识的获取具有了多种方式，但是高校所独有的校园文化是任何互 联网教育产品所无法替代的, 因此高校更应着力打造校园文化, 成为人文社区、创意摇篮与 互助学习社区。

人文社区: 深入传统文化教育, 实现课程化、标识化、活动化, 并融入到校园软环境的 建设中，建设以提升学生人文素养为目标的人文社区的环境;

创意摇篮：通过创业教育、创业大赛、创意工作坊、科技比赛等各种形式，实现各类创 新思想碰撞, 成为创新创意创业的 “三创” 摇篮;

互助学习社区: 充分发挥学生的长板原理, 组建以学生达人极客为核心的涉及文艺、体 育、科技等各类学生社团, 促进学生之间互助式的兴趣学习, 形成社会性成长的学习社区;

展示空间：通过公益活动向外界传递锦城文化; 积极参加各类赛事, 让学生的特长得到 充分的展示。

\section{5 组织与管理}

建立现代高效管理体制：运用互联网与信息技术，优化管理流程与制度，建立高效的以 教学科研为重心的管理体制。

柔性化组织结构: 为满足定制化服务与人才需求的高速变化的需求, 改变垂直化的组织 体系, 采用柔性化的组织结构如矩阵式组织结构, 促成创新教育、科研服务产品的供给, 促 进各专业间的复合化，提升教育服务供给的灵活性。

多元化的教师来源: 新技术的发展、学科的交融、国际的交流, 要求更加丰富教师来源, 建立多元学科、背景、国籍的师资队伍。

具有竞争力的激励机制：优质的教育基础在于优质的师资队伍，用具有行业竞争力的激 励机制与薪酬体系吸引应用型教学与科研的最优质的师资;

弹性化的雇佣方式: 教师的多元化必将要求雇佣模式的弹性化, 具体包括雇佣期限的弹 性化、工作内容的弹性化、工作时间的弹性化、工作地点的弹性化以及配套的管理措施。

多渠道的师资培训：为适应时代的要求，提升教师的信息与技术素养；提供国际交流平 台, 拓展国际视野; 建设双向进修制度与教师互助式学习的机制, 以促进复合型教师的成长。

社会化协同：对于部分前沿的专业与课程可采用社会化协同的方式，成为优质教育资源 的聚集中心; 对于部分非教育服务核心工作，采用外包专业公司以提升效率，集中人力资源 进行教育科研供给服务。

多主体参与学生事务决策机制: 在学生管理、学生活动等环节引入家长、用人单位等相 关主体共同参与决策的机制。

\section{6 品牌与公共关系}

教育品牌的提升: 提炼品牌的精髓, 细化规范以品牌核心价值为中心的品牌识别系统; 以品牌识别系统指导, 整合学校所有价值活动（宣传、招生、就业、教学、招聘、学生活动、 科研服务、对外交流等），传播核心价值；建立具有鲜明的核心价值与个性、丰富的品牌联 想、高知名度、高美誉度、高忠诚度的教育品牌, 累积品牌资产, 提升学校对学生的吸引力、 对教学科研人才的吸引力，对资本的吸引力。

公共关系的维护与拓展：维护与教育主管部门的关系; 建立与各行业协会的深度合作; 扩展校友会规模与区域; 建立与中学培训学校等生源机构的合作机制; 建立与各类媒体的良 好互动关系。

\section{7 监测与反馈机制}

建立基于大数据的内部监测：基于数据的检测, 强调了过程监管与实时预警, 用数据结 果改进教学与管理; 
建立用户反馈机制: 定期进行学生接受教育的满意度调查、用人单位的满意度调查, 通 过用户反馈改进服务与管理;

建立第三方监测机制: 引入第三方对学校的教学成果、科研成果、学生发展进行监测, 定期提供监测报告。

\section{5. 结束语}

未来的社会是智能化的社会，未来的教育也必将走向定制化。民办高校将以学习者的需 求为出发点, 通过互联网、大数据等技术重构我们的教育服务内容、教学方式、运作流程, 构建以教学科研为中心的柔性管理模式, 建立一个开放的、充满活力的互助式学习空间, 为 学习者提供更加个性化、更加精准的终身教育产品与服务。

\section{References}

[1] Research on the Development Strategy of Private Higher Learning Institution Based on the SWOT Analysis, Science Technology and Industry, vol.9, pp. 92-96, 2009.

[2] Research on Teaching Model Building of Higher Education Based on MOOC, JOURNAL OF DISTANCE EDUCATION, vol.4, pp. 65-71, 2015.

[3] An Analysis of Education-Decision Support Oriented by Educational Effectiveness: From the Perspective of Learning Analytics, Modern Distance Education Research, vol.6, pp. 41-48, 2014.

[4] Feature Analysis of Teachers in Digital Teaching Environment, Teacher Education Forum, vol. 29, pp. 10-15, 2016. 